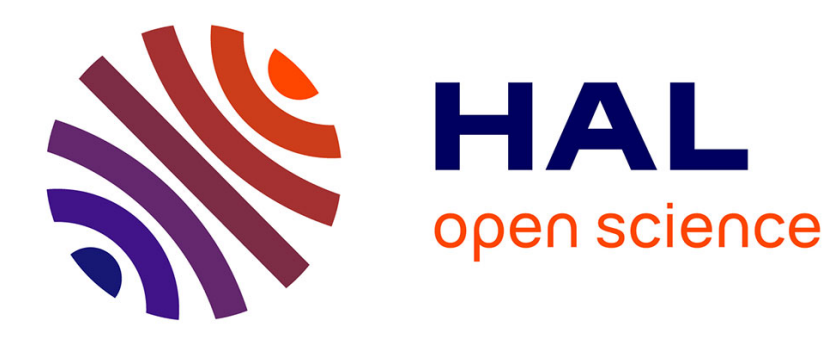

\title{
Shock Wave Use for Diamond Synthesis
}

\author{
V. Sobolev, Y. Taran, S. Gubenko
}

\section{To cite this version:}

V. Sobolev, Y. Taran, S. Gubenko. Shock Wave Use for Diamond Synthesis. Journal de Physique IV Proceedings, 1997, 07 (C3), pp.C3-73-C3-75. 10.1051/jp4:1997315 . jpa-00255438

\section{HAL Id: jpa-00255438 https://hal.science/jpa-00255438}

Submitted on 1 Jan 1997

HAL is a multi-disciplinary open access archive for the deposit and dissemination of scientific research documents, whether they are published or not. The documents may come from teaching and research institutions in France or abroad, or from public or private research centers.
L'archive ouverte pluridisciplinaire HAL, est destinée au dépôt et à la diffusion de documents scientifiques de niveau recherche, publiés ou non, émanant des établissements d'enseignement et de recherche français ou étrangers, des laboratoires publics ou privés. 


\title{
Shock Wave Use for Diamond Synthesis
}

\author{
V.V. Sobolev, Y.N. Taran* and S.I. Gubenko* \\ State Mining University of Ukraine, Prospekt K. Marksa 19, Dnepropetrovsk 320600, Ukraine \\ * State Metallurgical Academy of Ukraine, Prospekt Gagarina 4, Dnepropetrovsk 320635, Ukraine
}

\begin{abstract}
The possibility of diamond synthesis in gray iron is addressed for cases of plastic deformation preceding or thermal cycling following the shock wave loading of the iron samples. The physical properties of diamond single crystals thus synthesized are found to be similar to those of natural diamond.
\end{abstract}

Résumé. La possibilité de la synthèse de diamant dans la fonte grise est adressé pour la traitement par explosion combiné avec déformation plastique préalable ou bien avec traitement thermocyclique ultérieur de la fonte. Les monocristaux de diamant synthétisé sont semblables en propriétés physiques aux diamants naturels.

For explosive synthesis of diamond in cast iron, pressures in excess of $60 \mathrm{GPa}$ are required. Planar shock wave loading is normally employed for explosive processing of the cast iron samples involved. Diamond polycrystals with particle sizes ranging from 1 to $20 \mu \mathrm{m}$ are generally synthesized in cast irons and other carbon-bearing metal alloys. The average size of crystallites in the polycrystalline particles ranges from 0.005 to $0.020 \mu \mathrm{m}$.

The diamond crystallization in the entire bulk of a precursor graphite inclusion allows an explanation other than by cooperative rearrangement of atoms. Once the carbon atoms are excited to a high enough energy level, they will pass the potential barrier to a new equilibrium. When the directional chemical bonds are disrupted, a disordered inclusion (high-dense carbon gas) emerges that consists of excited carbon atoms. These form diamond nuclei within time intervals whose length is equal in the order of magnitude to lifetime of unpaired $s p^{3}$-electrons. This mechanism results in diamond particles comprised of multiple minute single crystals [1].

Diamonds synthesized by explosive processing differ from their natural or high-pressure synthetic counterparts in their microstructure, particle shape, and physical, chemical, mechanical and service properties.

It was found earlier [2] that the graphite stability region in the phase diagram of carbon can be divided into two parts, see Fig. 1. They are the diamond kinetic stability zone and the diamond thermodynamic instability zone in which diamond cannot ever exist.

Influence of preliminary plastic deformation of cast iron used for shock wave synthesis of diamond was studied previously together with the diamond morphology [3]. The experimentation involved two steps of metal working, namely hammer forging followed by explosive compression. The forging was performed at temperatures up to $1000 \mathrm{~K}$, and the degree of reduction was about $50 \%$. The forging step was aimed at producing supersaturated carbon solutions in iron and developing a thermodynamically metastable structure with high internal stored energy. The pressures that developed in cast iron during the explosive processing step were calculated to be $82 \mathrm{GPa}$, or $37 \mathrm{GPa}$ in a graphite inclusion traversed by a shock wave for a single time.

Diamond single crystals up to $0.35 \mathrm{~mm}$ in size were extracted from the cast iron samples following the forging and the dynamic compression. Also extracted were other minerals like quartz, rutile, 
almandine, moissanite, biotite, and eulyte. These minerals formed particles ranging from 0.05 to $1.00 \mathrm{~mm}$ in size.

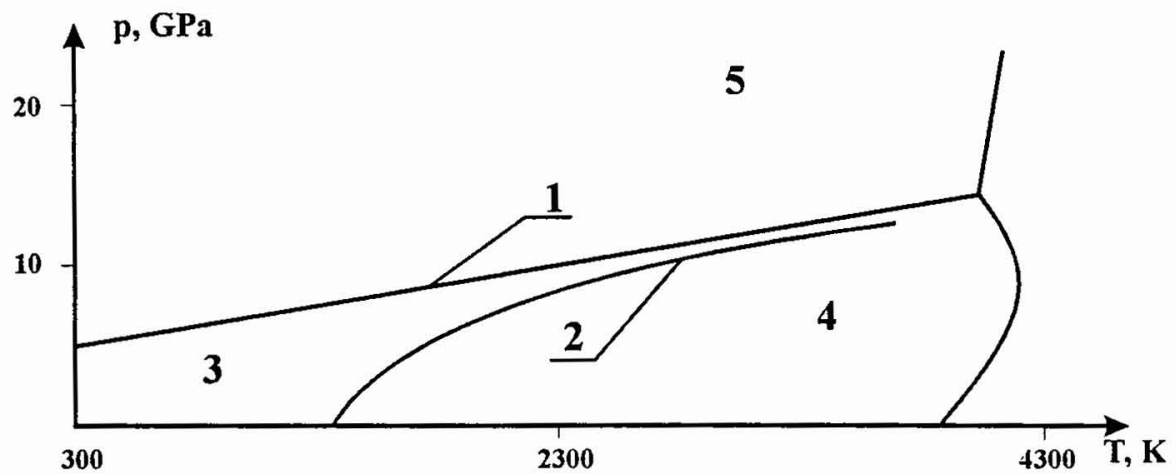

Figure 1: Carbon phase diagram. 1, graphite-diamond equilibrium line; 2, boundary between the kinetic stability zone (3) and the thermodynamic instability zone (4); 5, diamond thermodynamic stability region

For the first time in the history of diamond synthesis development, the properties of synthesized diamond were similar to those of natural diamond. Thus the synthetic diamond crystals were found to have a zonal structure of single crystals with a central zone featuring many crystal defects. When subjected to ultraviolet radiation, the diamonds emitted light-blue, yellowish-green or orange light. The transition region between the central zone and the periphery was depleted of nitrogen. Abnormally large differences as high as 0.7 to $0.9 \%$ were found between the carbon isotope ratios of the precursor graphite and the synthetic diamond. As regards thermal stability, the synthetic diamonds were similar to natural diamonds of e.g. Kokchetav massif.
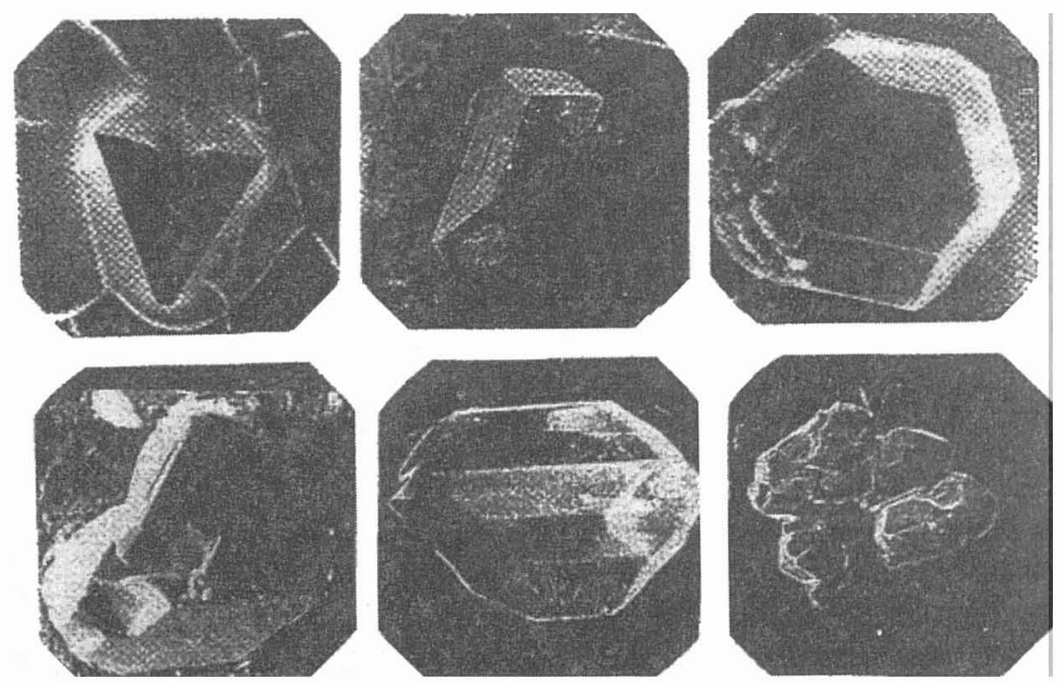

Figure 2: Diamond single crystals extracted from cast iron following explosive processing combined with other treatments like preforming or subsequent thermal cycling. $300 \times$

In another experimental study, thermal cycling of cast iron was carried out following explosive processing [5]. Comparison between the products revealed that many physical and chemical properties of 
diamond crystals produced by the forging-and-explosion process and the explosion-and-thermal-cycling process are closely or absolutely similar. Changing thermal cycling conditions (such as the rates of heating and cooling, the cycle amplitude, and the upper and lower temperature) affects crystal morphology and color, causes considerable variations in the compositions and concentrations of inclusions in crystals, and dramatically changes the quantitative characteristics of luminescence.

The synthetic crystals are normally octahedrons, less often cuboctahedrons, and very seldom rhombododecahedrons, see Fig. 2.

The mechanism of diamond growth on explosion-initiated polycrystalline nuclei includes unmixing of carbon supersaturated solution both in shock wave heating of predeformed samples and in thermal cycling of explosive-processed cast iron. Owing to the high density of crystal defects, such as vacancies and dislocations, the diffusion phenomena occur at high rates within iron grains and along interfaces and grain boundaries alike. The unmixing is initiated by a temperature rise due to the dynamic compression in the first case and by alternating heating and cooling of the iron matrix in the second case. Thus the available degree of cast iron structure metastability that can be expressed in terms of the amount of additional stored energy in a way determines the potential for growth or the activity of the growth medium. Such a system does not need a transition to high pressures and temperatures for the diamond polycrystals to continue their growth.

In summary, it may be said that diamond thus was discovered to be capable of growth in a solid, provided that the solid medium either contains carbonaceous phases or forms carbon solid solutions below $1500 \mathrm{~K}$, i.e. in the region where diamond is thermodynamically metastable and only kinetically stable, see Fig. 1.

The role of shock wave consists in causing a phase transformation in graphite via either the graphite $\rightarrow$ diamond or the graphite $\rightarrow$ high-dense carbon gas $\rightarrow$ diamond reaction. The subsequent growth of diamond occurs at low levels of the thermodynamic parameters that may be also typical of diamond formation in nature [4].

\section{References}

[1] Sobolev V.V., Slobodskoi V.Ya. and Egorov P.A., Chemical physics of combustion and explosion processes. Detonation (Ob'edinennyi Insititut Khimicheskoi Fiziki, Chernogolovka, 1989) pp.69-72. In Russian.

[2] Slobodskoi V.Ya. and Sobolev V.V., Khimicheskaya Fizika 8 (1989) 1137-1141.

[3] Sobolev V.V., Slobodskoi V.Ya. and Kozlov I.T., Fizika i tekhnika vysokikh davlenii 26 (1987) 7-9.

[4] Sobolev V.V. and Slobodskoi V.Ya., Zapiski Vsesoyuznogo mineralogicheskogo obshchestva 3 (1992) 118-124.

[5] Sobolev V.V., Taran Yu.N. and Gubenko S.I., Metallovedenie i termicheskaya obrabotka metallov, 1 (1993) 2-6. 